\title{
The Influence of Utilizing Recycled and Reclaimed Coarse Aggregates in Producing Concrete for Structural Applications
}

\author{
Saied KASHKASH, Zoltan ORBAN*, Oliver CZOBOLY
}

\begin{abstract}
Utilizing recycled or reclaimed coarse aggregates in producing recycled concrete for structural applications helps in preserving natural resources from depletion and reduces the volume of waste created throughout construction and demolition. Recycling makes the concrete production more sustainable and environment-friendly, by narrowing the traditionally vast area needed to be occupied as landfills. In this research, four types of mixes were prepared using recycled concrete aggregates and reclaimed crushed aggregates as substitution of natural coarse aggregates in different replacement percentages. Series of tests were conducted to investigate the properties of fresh and hardened concrete samples prepared from mixes with various compositions. The effects of adding recycled or reclaimed aggregates are presented in this paper. The results reveal that recycled concrete with $50 \%$ replacement of natural coarse aggregates with recycled or reclaimed aggregates can have adequate fresh and hardened properties. However, with full replacement ratio, although the compressive strength of recycled concrete was higher than that of conventional concrete, the workability of the recycled concrete mix significantly decreased.
\end{abstract}

Keywords: fresh and hardened concrete; reclaimed crushed aggregate; recycled concrete aggregate; recycled concrete

\section{INTRODUCTION}

Development of building and construction industry plays an essential role in satisfying the growing needs of humanity driven by the rapid increase in population and urbanism. As this development permanently grows, it escalates the rates of consuming the natural materials and has a deleterious effect on the environment. Concrete has been widely considered as the most efficient construction material for different types of structures in the construction industry. Thus, tremendous amounts of concrete are being consumed around the World [1]. Even though concrete is characterized by very profitable advantages ranging from very good compressive strength, durability, fire resistance, cost-effectiveness and availability, the continuous production of conventional concrete (i.e. concrete produced from natural virgin aggregates and portland cement) has been proven to negatively affect the environment as a result of exhausting the natural resources besides the $\mathrm{CO}_{2}$ emissions from the cement production [23]. Furthermore, a challenging problem arises when a huge volume of construction and demolition waste $(C \& D W)$ is created as a result of regular urban development when new structures replace old ones [4]. In Europe, according to FIR (Fédération Internationale du Recyclage), the (C \& DW) approximately account for $30 \%$ of the total waste volume [5].

Producing recycled aggregates by conducting treatments and processes on C \& DW is not absolutely new; according to the European Aggregates Association report in 2019, about $12 \%$ of the total aggregate production in the European region was from recycled and reused aggregates [6]. Although it is allowed by the European Standard (EN-206) to use recycled aggregate (recommendation: up to $50 \%$ recycled coarse aggregate in concrete, depending on the exposure classes and the properties of the aggregate), the utilization of recycled aggregates is still limited to low-grade applications or road constructions in most of the European countries [7]. Recycled aggregates are classified depending on their size as coarse $(D>4 \mathrm{~mm})$ and fine $(D \leq 4 \mathrm{~mm})$. The size of the recycled aggregate characterizes its properties and consequently the field of application. There is a significant difference between the properties of recycled coarse aggregate and recycled fine aggregate that contains more amount of attached mortar [8]. Accordingly using fine aggregate in producing concrete is not recommended since it causes a reduction in workability and strength of the recycled concrete [8-10]. Excluding the presence of other contaminants, water absorption and density are the two main properties to assess the quality of the coarse aggregate as these properties are related to the adhered mortar that causes undesirable effects [11].

Using recycled coarse aggregate as a replacement of natural aggregate in producing concrete for structural applications has been investigated by many researchers [12-18]. However, in many cases the available results are incomparable due to a large variety of variables such as w/c ratio, water-reducing admixtures and the mixing methods used in the tests. Otsuki et al. [19] addressed the correlation between expected compressive strength and the bond between the old mortar and gravels in the recycled aggregates considering the $\mathrm{w} / \mathrm{c}$ ratio. Khaldoun in [16] proposed that the compressive strength of recycled concrete is not limited to the strength of the demolished concrete that was used to obtain the recycled aggregate. While Bui et al. [20] indicated that recycled aggregate percentage is conversely proportional to the compressive strength, several authors [13, 14, 21, 22] have reported that the usage of recycled aggregate of up to $25-30 \%$ replacement is appropriate to produce concrete for structural applications. In other studies [12, 23, 24] the authors indicated that the compressive strength was not influenced by the replacement percentage when a good quality recycled aggregates were used. Hence, a wide range of research has been carried out to compare the performance of recycled concrete with normal concrete, and a few studies have investigated the influence of reclaimed and recycled aggregates on the performance of recycled concrete for structural applications. Therefore, more research is needed to verify the effects of using recycled and reclaimed aggregates - with higher substitute levels than recommended by standards - on the fresh and hardened properties of recycled concrete. Also, solutions 
should be found to improve these properties to make the performance of recycled concrete similar to that of the conventional one. In this paper, the experimental program aims to investigate the mechanical properties of recycled concrete incorporating reclaimed crushed or recycled aggregates recovered from demolition waste.

\section{MATERIALS}

Natural coarse aggregate $(\mathrm{N})$ : normal natural aggregate with a rounded shape and a smooth surface from a local supplier. Separated in two fractions: $4 / 8 \mathrm{~mm}$ (fineness modulus: 6.98, Category: $\mathrm{G}_{\mathrm{C}} 85 / 20 \mathrm{f1.5}$ ) and 8/16 mm (fineness modulus: 7.94 , Category: $\mathrm{G}_{\mathrm{C}} 85 / 20 \mathrm{f1} .5$ ). See Fig. 1a.

Recycled coarse aggregate (RCY): These rubbles were collected from the waste of a demolished high-rise building that was built in the 1970s and demolished in 2012 in Pécs, Hungary. After the primary crushing, the sizes of the concrete pieces were about $60 \mathrm{~mm}$ to $100 \mathrm{~mm}$. Then an impact crushing was used to reduce the size of the aggregate, and finally, the aggregate was sieved to separate it into the required sizes. These aggregates are categorized as type "A" aggregate according to EN 206 since more than $90 \%$ of the materials are considered demolished concrete. See Fig. $1 b$.

Reclaimed crushed coarse aggregate (REC): obtained by an impact crushing of lab-test-cubes with different grades (from C20/25 to C35/45). See Fig. 1c. The cubes were collected after conducting compressive strength tests from the quality-control laboratory in Hungary "A-Beton". After crushing the cubes, the resulted aggregates were sieved and separated according to their sizes. This type of aggregate is also categorized as type A according to EN 206.

Fine aggregate: The same type of natural sand is used in all mixes, the grading curve category is $\mathrm{G}_{\mathrm{F}} 85 \mathrm{f} 3$.

Cement: the used cement is type CEM II/B-S $42.5 \mathrm{~N}$ for all mixes produced by Duna-Dráva Cement Ltd. (Vác industry) and complied with EN197-1 without any cementitious replacement.

Chemical admixtures: water-reducing admixture is used to achieve the desired workability. The type of superplasticizer used is Sika Viscocrete 7710, (the recommended dosage between $0.2-2 \mathrm{~m} \%$ of the cement).

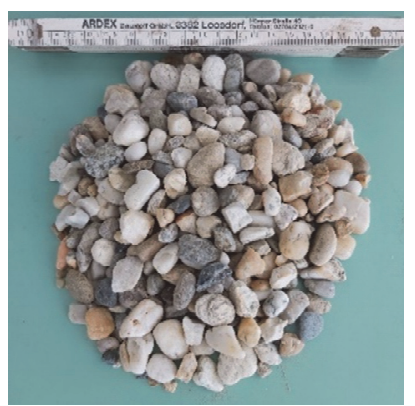

(a) Natural Aggregates $\mathrm{N}$

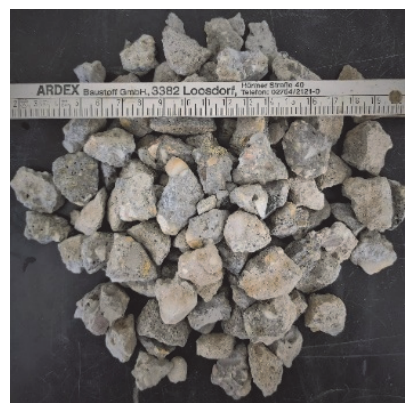

(b) Recycled Aggregates REY

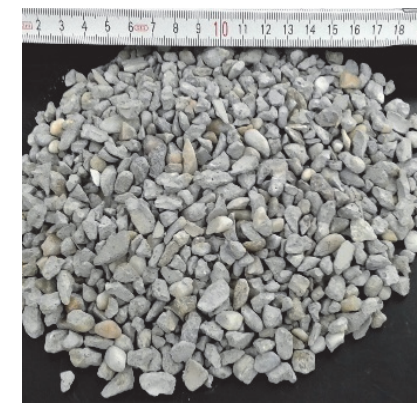

(c) Reclaimed Aggregates REC

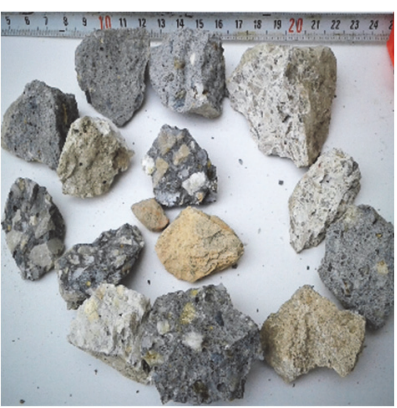

(d) Contaminants Bricks tiles etc.

\section{EXPERIMENTAL PROGRAM 3.1 Concrete Mixes}

Four concrete mixes with deferent content of coarse aggregates - shown in 0 - were prepared to investigate the effect of each type of coarse aggregate on the properties of concrete. Mix D4 was done to investigate the full replacement of natural coarse aggregate $(\mathrm{N})$ with the reclaimed aggregate (REC) from crushed test-cubes. Mix D2 and Mix D3 were prepared to compare the concrete made with reclaimed crushed aggregate (REC) with the one incorporating recycled aggregate (RCY) at a $50 \%$ substitution ratio.

Table 1 Coarse aggregate ratio in each mix

Table 1 Coarse aggregate ratio in each mix
\begin{tabular}{|c|c|c|c|}
\hline Mix code & REC & RCY & N \\
\hline Mix D1 & - & - & $100 \%$ \\
\hline Mix D2 & - & $50 \%$ & $50 \%$ \\
\hline Mix D3 & $50 \%$ & - & $50 \%$ \\
\hline Mix D4 & $100 \%$ & - & - \\
\hline
\end{tabular}

The targeted concrete strength was C30/37 and the desired consistency class was plastic (flow: 400-440 mm). The absolute volume method was adopted to design the mix proportions of the concrete compositions. The concrete mixtures proportions are shown in 0 . Mixture proportions were determined in accordance with the following concept:

The cement type and content were the same in all mixtures. The water/cement ratio was the same in all mixes $(\mathrm{w} / \mathrm{c}=0.52)$. The source, size distribution, and wetness condition of the natural coarse or fine aggregate were the same in all mixes. The Maximum diameter of the coarse aggregate was $d_{\max }=16 \mathrm{~mm}$. The grading curves of the natural coarse, reclaimed, and recycled aggregates were similar. The mixing method was the same for all mixes in terms of the sequence of adding materials and the mixing time. The natural coarse and fine aggregates were in ovendried condition while the recycled and reclaimed aggregates were in their original condition (air-dried condition) without saturation or adding any additional water.

The physical properties of these aggregates were tested (particle density and water absorption of crushed aggregate complying with EN1097-6). The results of the test are shown in Tab. 3. The grading curves of the aggregates are presented in Fig. 2. These curves are produced in accordance to EN 933-1. The presence of other contaminants like wood, paper, tiles, bricks and metal debris was noticed in RCY type, see Fig. 1d. The total mass of these contaminants was less than $10 \%\left(R_{\mathrm{c}} 90\right.$ and $\left.R_{\mathrm{cu}} 95\right)$ which makes it type A. Only coarse aggregate with sizes 
between (4-16) $\mathrm{mm}$ was classified into two standard fractions of coarse aggregate, namely the $4 / 8 \mathrm{~mm}$ and $8 / 16$ $\mathrm{mm}$ form $44 \%, 56 \%$ respectively of the coarse aggregate volume. The volume of the different aggregate fractions was the same in each mixture. $0 / 4$ fraction $40 \%, 4 / 8$ fraction $26 \%$ and $8 / 16$ fraction $34 \%$.

\subsection{Concrete Batching Procedure}

The mixing procedure was adapted based on the described goals and was as practical as possible. A pan type mixer with 50 litres capacity was used for the preparation of all concrete mixtures.

The conventional mixing approach was applied by adding the coarse aggregate, then the cement, followed by sand in order to cover the cement and prevent it from dusting. After that, a dry mixing was continued for about 30-60 seconds, then the water was added gradually during the mixing and was distributed equally. The wet mixing lasted for about 1-2 minutes during which different dosages of the superplasticizer were gradually added to the mixture to achieve the targeted workability. This last step was repeated until reaching the desired properties of the fresh concrete.

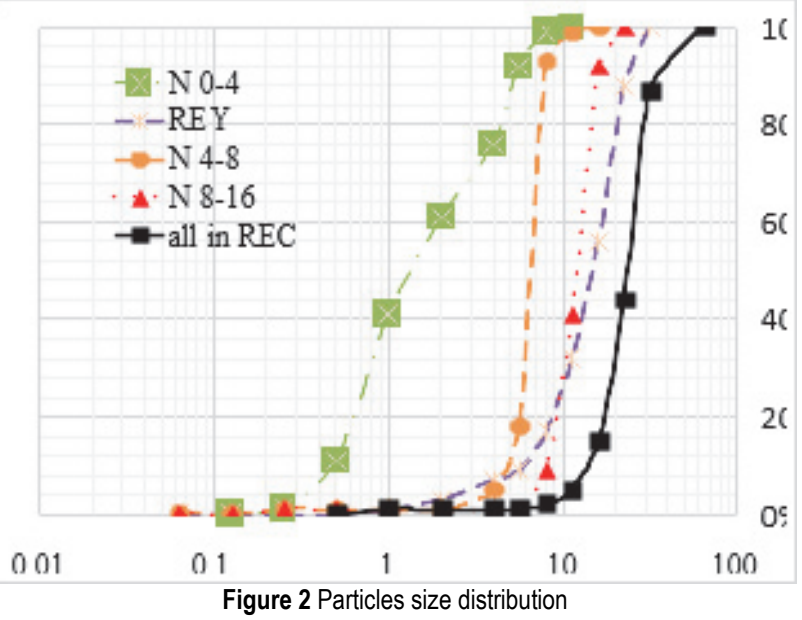

Table 2 Concrete Mix proportions for $1 \mathrm{~m}^{3}$ concrete

\begin{tabular}{|c|c|c|c|c|c|c|c|c|c|}
\hline \multirow{2}{*}{$\begin{array}{l}\text { Concrete } \\
\text { Mixture }\end{array}$} & \multirow{2}{*}{ Cement / kg } & \multirow{2}{*}{ Water / kg } & \multirow{2}{*}{$\mathrm{w} / \mathrm{c}$} & \multirow{2}{*}{ Sand / kg } & \multicolumn{3}{|c|}{ Coarse Aggregate / kg } & \multirow{2}{*}{ Plasticizer / kg } & \multirow{2}{*}{$\begin{array}{c}\text { Density / } \\
\mathrm{kg} / \mathrm{m}^{3}\end{array}$} \\
\hline & & & & & $\mathrm{N}$ & RCY & REC & & \\
\hline Mix D1 & 350 & 182 & 0.52 & 732 & 1098 & - & - & 0.86 & 2363 \\
\hline Mix D2 & 350 & 182 & 0.52 & 732 & 549 & 495 & - & 1.43 & 2310 \\
\hline Mix D3 & 350 & 182 & 0.52 & 732 & 549 & - & 506 & 1.72 & 2320 \\
\hline Mix D4 & 350 & 182 & 0.52 & 732 & - & - & 1012 & 4.57 & 2276 \\
\hline
\end{tabular}

\subsection{Tests on Concrete Mixes}

\subsubsection{Fresh Concrete Properties}

1. The flow table test was prepared according to EN 12350-5:2009 to determine the consistency class of fresh concrete.

2. The fresh density of the concrete was measured and calculated according to EN 12350-6:2009.

3 . The air content was measured with the pressure gauge method according to EN 12350-7:2009.

\subsubsection{Hardened Concrete Properties}

1. The compressive strength was determined according to EN 12390-3:2009 using three standard size $(150 \mathrm{~mm})$ cubical specimens from each mix at 28 days of age. The specimens were immersed in water for 7 days before they were cured in air condition (according to the Hungarian standard, MSZ 4798:2016).

2. The hardened density of the concrete was calculated according to EN 12390-7:2009.

3 . The water penetration test was performed according to EN 12390-8:2009 to determine the maximum water penetration depth under pressure $(5$ bars pressure for 72 hours).

\section{RESULTS AND DISCUSSION \\ 4.1 Characteristics of Recycled and Reclaimed Coarse Aggregate}

The tests show that the physical properties of the recycled aggregates differ from those of natural aggregates, especially the water absorption and the density. The water absorption of RCY and REC was 5-8 times higher than $\mathrm{N}$ and the specific density of REC/RCY was $7-10 \%$ lower than $\mathrm{N}$ aggregate (see Tab. 3). These results are in line with previous studies and mainly induced by the presence of the old residual adhered cement-paste, which has less density and its structure contains more pores and more voids than the natural aggregate $[10,25,26]$. Furthermore, the physical properties of REC type aggregates were slightly better than the REY type properties (see Fig. 3).

Table 3 Coarse aggregate density and water absorption

\begin{tabular}{|c|c|c|c|c|c|c|}
\hline \multirow{2}{*}{$\begin{array}{c}\text { Type } \\
\text { Fraction }\end{array}$} & $4 / 8$ & $8 / 16$ & $4 / 8$ & $8 / 16$ & $4 / 8$ & $8 / 16$ \\
\hline $\begin{array}{c}\text { Density } \\
/ \mathrm{g} / \mathrm{cm}^{3}\end{array}$ & 2.63 & 2.64 & 2.36 & 2.39 & 2.41 & 2.44 \\
\hline $\begin{array}{c}\text { Water } \\
\text { absorption / \% }\end{array}$ & 1.2 & 1.1 & 7.6 & 6.2 & 5.1 & 4.4 \\
\hline
\end{tabular}

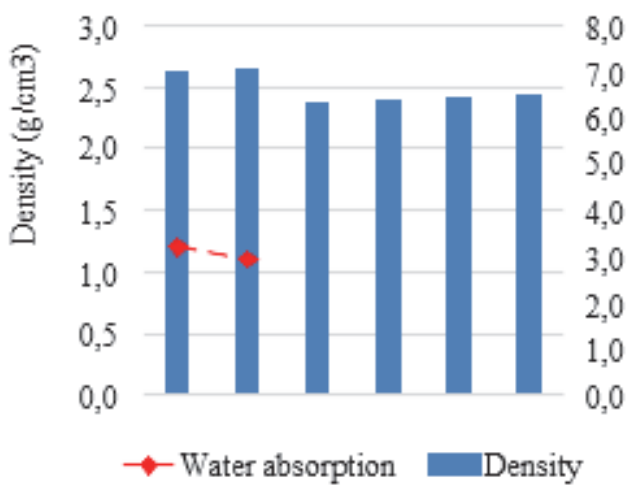

Figure 3 Water absorption vs density

This improvement in the properties is mainly related to the mortar content and the quality of the original aggregates. In addition to the density and water absorption, 
the particle shape of the recycled and reclaimed aggregates is angular irregular with rough surface texture, which differs from the used natural rounded aggregate having a smooth surface. This fact has an impact on the fresh concrete properties $[25,27]$.

\subsection{The Fresh Concrete Properties 4.2.1 Workability}

The flow table test was conducted immediately after the mixing. The results are shown in Tab. 4. The workability of recycled concrete incorporating 100\% reclaimed crushed coarse aggregate (Mix D4) was significantly decreased and did not meet the targeted flow range (see Fig. 4). This deviation is mainly caused by the higher water absorption of the reclaimed aggregate that absorbs water from the mix reducing the effective water content and workability of the concrete. This result is consistent with the conclusions of previous studies [24], [27]. Other factors that may have accounted for the lower workability are the rough texture and the angular shape with more pores in the recycled aggregate, as more cement paste is required. Previous studies addressed that using natural rounded aggregate with a smooth surface gives better workability than crushed angular aggregate [28]. By Mix D2 with $50 \%$ of RCY, similar workability was achieved with a higher dosage of superplasticizer. However, at the same replacement percentage, a lower workability class was achieved with REC aggregate type (Mix D3) even with a higher dosage of superplasticizer (see Fig. 5).

\subsubsection{Air Content}

The results of measured air content and fresh density of recycled concrete are shown in Tab. 4. According to the test results, with substitution of up to $50 \%$ of natural coarse aggregate, there was no observable variation in the air content of fresh concrete; while with full replacement of $\mathrm{N}$ with REC, the air content remarkably increased.

Table 4 Fresh properties of concrete mixes

\begin{tabular}{|c|c|c|c|c|c|}
\hline Mix Code & $\begin{array}{l}\text { Superplasticizer } \\
\text { quantity } / \mathrm{m}_{\mathrm{c}} \%\end{array}$ & Flow diameter / $\mathrm{mm}$ & $\begin{array}{l}\text { Fresh concrete density / } \\
\mathrm{kg} / \mathrm{m}^{3}\end{array}$ & Consistency class & Air Content \\
\hline Mix D1 & 0.25 & 440 & 2372 & F3 & $1.4 \%$ \\
\hline Mix D2 & 0.43 & 430 & 2325 & F3 & $1.2 \%$ \\
\hline Mix D3 & 0.5 & 400 & 2357 & $\mathrm{~F} 2$ & $1.4 \%$ \\
\hline Mix D4 & 1.35 & 300 & 2330 & $\mathrm{~F} 1$ & $2.2 \%$ \\
\hline
\end{tabular}

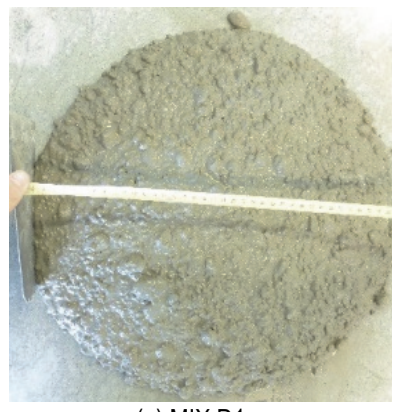

(a) MIX D1

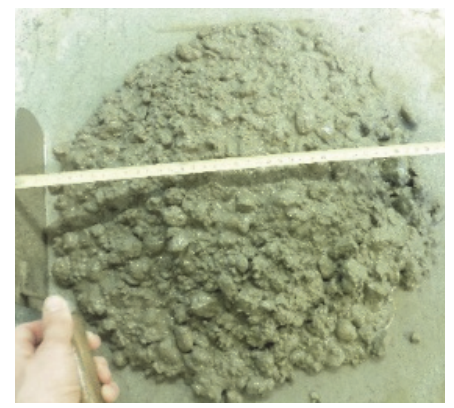

(b) MIX D2

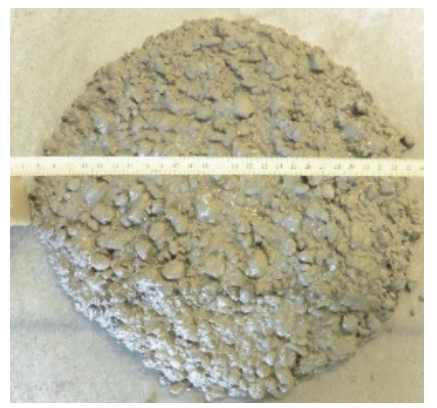

(c) MIX D3

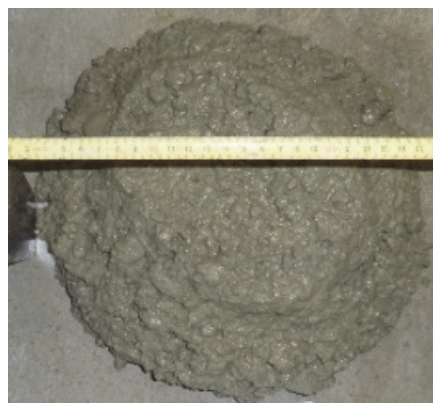

(d) MIX D4

Figure 4 Flow table test results

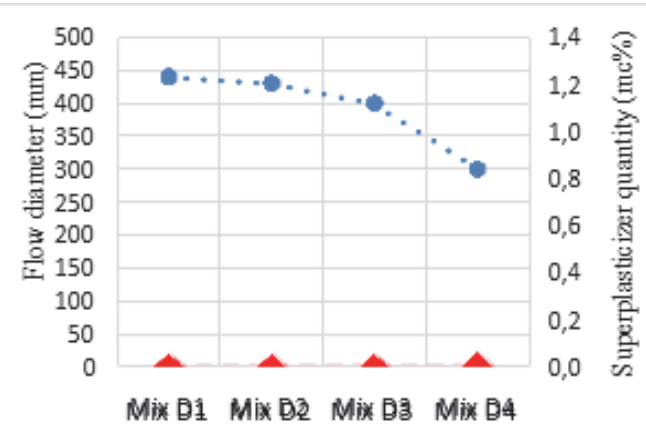

-४-Quantity of Superplasticizer * Flow diameter

Figure 5 Flow vs superplasticizer

\subsection{Hardened Properties of Recycled Concrete 4.3.1 Compressive Strength}

In this research, the reclaimed/recycled aggregates were used in their original condition (air-dried condition) without saturation or adding any additional water to the mix to avoid the loss in compressive strength [29]. The average values of the compressive strength at 28 days are presented in Fig. 6. The compressive strength of the recycled concrete incorporating $100 \%$ and $50 \%$ reclaimed coarse aggregate was higher than the compressive strength of conventional concrete with about $45 \%$ and $21 \%$ respectively. By increasing the replacement ratio of reclaimed aggregate, the compressive strength of recycled concrete increased as well. This confirms that a higher replacement ratio does not necessarily result in lower concrete strength, contrary to its effect on the air content. The increase in the compressive strength could mainly be caused by a lower effective w/c ratio since the recycled and reclaimed aggregates absorb more water than natural aggregate, therefore it reduces the effective $\mathrm{w} / \mathrm{c}$ ratio and increases the compressive strength. Furthermore, the same replacement ratio of recycled aggregate introduced lower compressive strength than reclaimed aggregates. This reduction in compressive strength may result from the 
existence of contaminants in the recycled aggregate. The results demonstrate that it is possible to produce high strength recycled concrete when good quality recycled aggregate and a proper mixing method are combined.

\subsubsection{Hardened Concrete Density}

The hardened concrete density of REC was lower than that of N. However, there was no significant difference between the density of the hardened recycled and hardened conventional concrete (Mix D3 and Mix D1) when the air content was similar, see Fig. 6. The aggregate density of RCY type was lower than that of the REC type aggregate. Thus, the hardened concrete density of Mix D2 was lower than Mix D3. The lowest hardened concrete density was by Mix D4. This reduction in the density is mainly caused by the high air content.

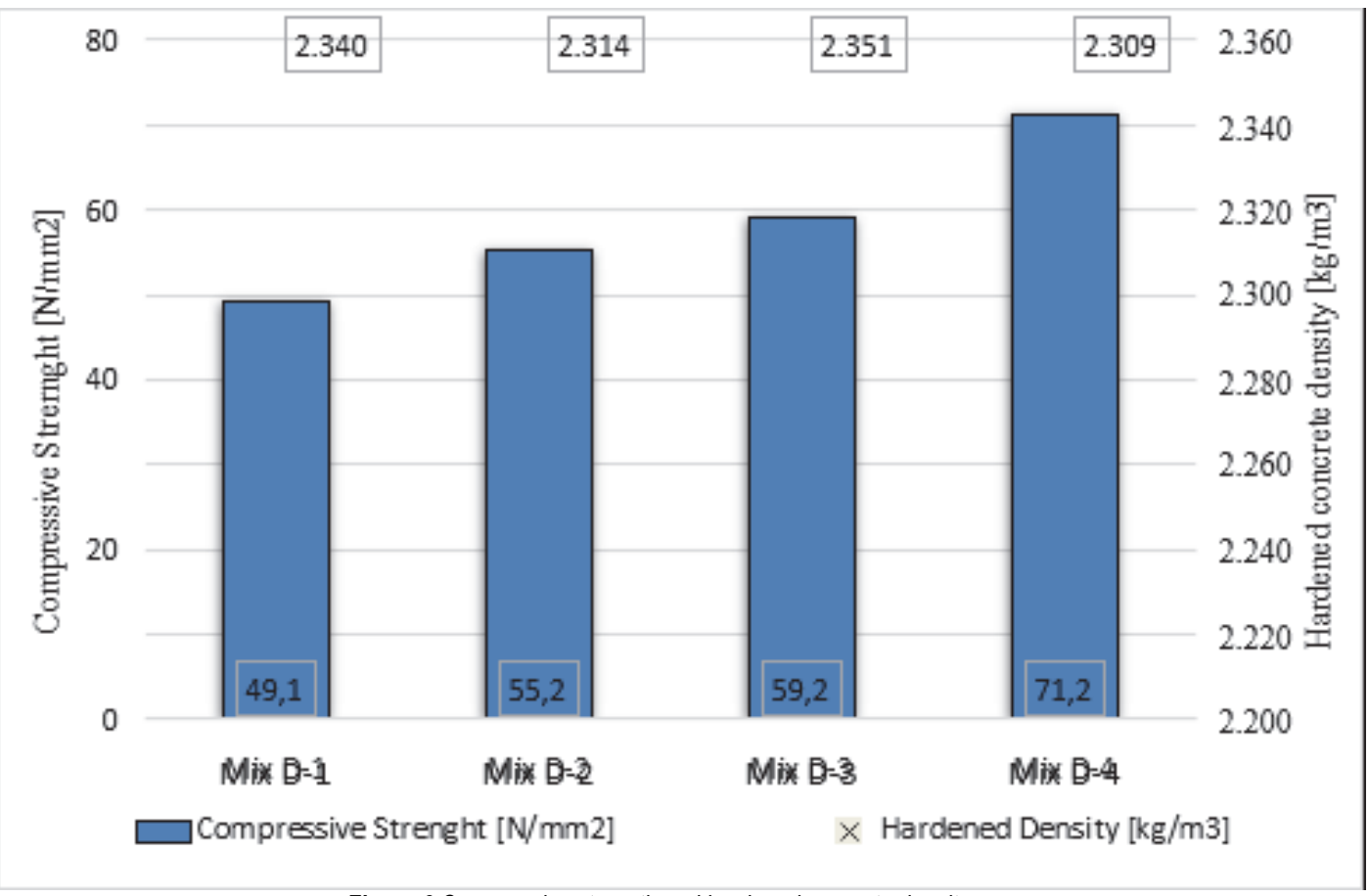

Figure 6 Compressive strength and hardened concrete density

\subsubsection{Water Penetration Depth}

The depth of water penetration decreased with the increase of REC replacement ratio as shown in Fig. (7). The trends are similar to the results reported by other studies [30]. The reason could be the ability of the REC to keep the water in and the low saturation level.

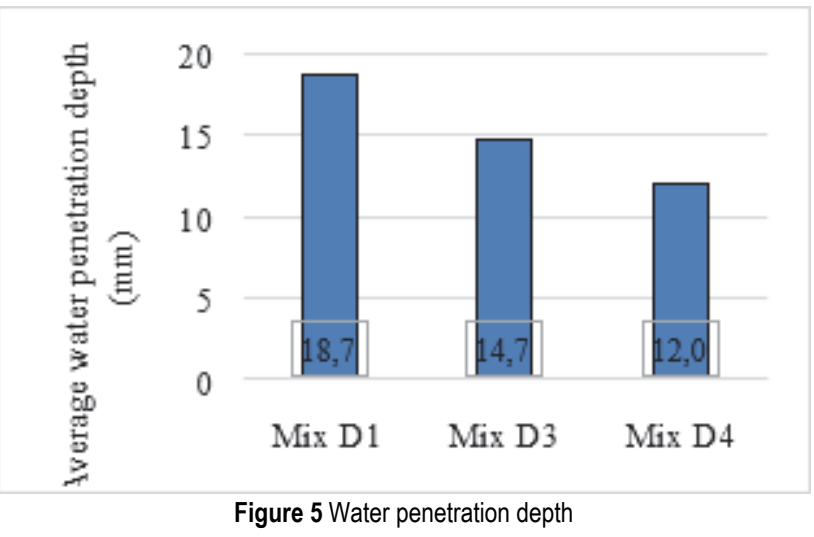

\section{CONCLUSION}

The main purpose of the carried-out study was to determine the effect of replacing natural coarse aggregate with recycled or reclaimed crushed aggregates. The main conclusion that can be drawn from the experiment is that recycled and reclaimed aggregates can provide adequate valuable alternatives to natural coarse aggregate not only for low-grade concrete applications but also producing concrete for structural applications. It should be noted however that this conclusion is valid under the conditions of this experiment with special consideration for the durability requirements. Despite the fact that the physical properties of natural aggregate are better than those of recycled one, the analysis of these differences has to be considered alongside with the environmental and sustainability aspects.

- A significant (approx. 45\%) increase in the compressive strength of recycled concrete was achieved with $100 \%$ reclaimed aggregate compared to reference conventional concrete while the compressive strength of recycled concrete with $50 \%$ recycled and $50 \%$ reclaimed coarse aggregate substitution was $12 \%$ and $20 \%$ higher than the strength of conventional concrete, respectively.

- The influence of reclaimed aggregate in terms of compressive strength was better than that of recycled aggregate. This effect could be related to a difference in the quality of aggregate in addition to the presence of other contaminants among the recycled aggregate.

- The workability of recycled concrete incorporating up to $50 \%$ substitution ratio was approximately similar to the workability of the conventional reference, while a significant decrease was found with $100 \%$ reclaimed coarse aggregate substitution. 
- The water penetration depth of the recycled concrete was lower than the penetration depth of the conventional one.

- The use of superplasticizer to enhance the workability of recycled concrete was found to be effective up to $50 \%$ replacing ratio of the coarse natural aggregate without adding extra water to the mix.

Based on the results of the experiments, it can be deduced that it is extremely important to determine the amount of the water absorbed by the recycled/reclaimed aggregate, and also find the relationship between the volume of the attached old mortar in the composition and the amount of absorbed water. Another interesting question for future research is to determine the durability and pumpability of recycled concrete.

\section{Acknowledgements}

The research project is conducted at the University of Pécs, Hungary, within the framework of the Biomedical Engineering Project of the Thematic Excellence Programme 2019 (TUDFO/51757-1/2019-ITM).

\section{REFERENCES}

[1] Scrivener, K. L. (2014). Options for the future of cement. The Indian Concrete Journal, 88(7), 11-21.

[2] Andrew, R. M. (2018). Global CO2 emissions from cement production, 1928-2017. Earth System Science Data, 10(4), 2213-2239. https://doi.org/10.5194/essd-10-2213-2018.

[3] Worrell, E., Price, L., Martin, N., Hendriks, C., \& Meida, L. O. (2001). Carbon dioxide emissions from the global cement industry. 1. Annual Review of Energy and the Environment, 26, 303-329. https://doi.org/10.1146/annurev.energy.26.1.303

[4] Katz, A. (2004). Treatments for the improvement of recycled aggregate. Journal of Materials in Civil Engineering, 16(6), 597-603. https://doi.org/10.1061/(ASCE)0899-1561(2004)16:6(597)

[5] Lotfi, S., Eggimann, M., Wagner, E., Mróz, R., \& Deja, J. (2015). Performance of recycled aggregate concrete based on a new concrete recycling technology. Construction and Building Materials, 95, 243-256. https://doi.org/10.1016/j.conbuildmat.2015.07.021

[6] European aggregates association. (2019). Annual Review 2018-2019. Annual Review. https://doi.org/10.7557/2.31.2.1982

[7] Šešlija, M., Radović, N., Jovanov, D., Kukaras, D., StarčevĆurčin, A., \& Jokanović, I. (2018). Possibilities of pervious concrete application in road construction. Tehnicki Vjesnik, 25(4), 1202-1212. https://doi.org/10.17559/TV-20160524162507

[8] Kang, M. \& Weibin, L. (2018). Effect of the aggregate size on strength properties of recycled aggregate concrete. Advances in Materials Science and Engineering, 2018. https://doi.org/10.1155/2018/2428576

[9] Lotfy, A. \& Al-Fayez, M. (2015). Performance evaluation of structural concrete using controlled quality coarse and fine recycled concrete aggregate. Cement and Concrete Composites, 61, 36-43. https://doi.org/10.1016/j.cemconcomp.2015.02.009

[10] de Juan, M. S. \& Gutiérrez, P. A. (2009). Study on the influence of attached mortar content on the properties of recycled concrete aggregate. Construction and Building Materials, 23(2), 872-877. https://doi.org/10.1016/j.conbuildmat.2008.04.012

[11] Pedro, D., De Brito, J. \& Evangelista, L. (2014). Influence of the use of recycled concrete aggregates from different sources on structural concrete. Construction and Building Materials, 71(2014), 141-151.

https://doi.org/10.1016/j.conbuildmat.2014.08.030

[12] Malešev, M., Radonjanin, V., \& Marinković, S. (2010). Recycled concrete as aggregate for structural concrete production. Sustainability, 2(5), 1204-1225. https://doi.org/10.3390/su2051204

[13] Wagih, A. M., El-Karmoty, H. Z., Ebid, M., \& Okba, S. H. (2013). Recycled construction and demolition concrete waste as aggregate for structural concrete. HBRC Journal, 9(3), 193-200. https://doi.org/10.1016/j.hbrcj.2013.08.007

[14] Corinaldesi, V. (2011). Structural concrete prepared with coarse recycled concrete aggregate: From investigation to design. Advances in Civil Engineering, 2011, 1-7. https://doi.org/10.1155/2011/283984

[15] Tabsh, S. W. \& Abdelfatah, A. S. (2009). Influence of recycled concrete aggregates on strength properties of concrete. Construction and Building Materials, 23(2), 11631167. https://doi.org/10.1016/j.conbuildmat.2008.06.007

[16] Rahal, K. (2005). Mechanical properties of concrete with recycled coarse aggregate. Building and Environment, 42(January 2007), 407-415. https://doi.org/10.1016/j.buildenv.2005.07.033

[17] Ramadevi, K. \& Chitra, R. (2017). Concrete using recycled aggregates. International Journal of Civil Engineering and Technology, 8(9), 413-419.

[18] Motwani, P., Rajendhiran, Elumalai, A., \& Santhi, A. S. (2013). High strength concrete using recycled aggregate. International Journal of Applied Engineering Research, 8 (19 spec. issue), 2501-2506.

[19] Yehia, S., Helal, K., Abusharkh, A., Zaher, A., \& Istaitiyeh, H. (2015). Strength and Durability Evaluation of Recycled Aggregate Concrete. International Journal of Concrete Structures and Materials, 9(2), 219-239. https://doi.org/10.1007/s40069-015-0100-0

[20] Bui, N. K., Satomi, T., \& Takahashi, H. (2017). Improvement of mechanical properties of recycled aggregate concrete basing on a new combination method between recycled aggregate and natural aggregate. Construction and Building Materials, 148, 376-385. https://doi.org/10.1016/i.conbuildmat.2017.05.084

[21] G, J. M., \& G, D. C. (2019). Durability Parameters of Reinforced Recycled Aggregate Concrete: Case Study. Applied Sciences, 9(4), 617-630. https://doi.org/10.3390/app9040617

[22] Etxeberria, M., Marí, A. R., \& Vázquez, E. (2007). Recycled aggregate concrete as structural material. Materials and Structures/Materiaux et Constructions, 40(5), 529-541. https://doi.org/10.1617/s11527-006-9161-5

[23] Yaragal, S. C., Teja, D. C., \& Shaffi, M. (2016). Performance studies on concrete with recycled coarse aggregates. Advances in Concrete Construction, 4(4), 263-281. https://doi.org/10.12989/acc.2016.4.4.263

[24] Abdulla, N. A. (2015). Effect of recycled coarse aggregate type on concrete. Journal of Materials in Civil Engineering, 27(10), 1-9. https://doi.org/10.1061/(ASCE)MT.1943-5533.0001247

[25] Poon, C. S. \& Chan, D. (2007). The use of recycled aggregate in concrete in Hong Kong. Resources, Conservation and Recycling, 50(3), 293-305. https://doi.org/10.1016/j.resconrec.2006.06.005

[26] Wardeh, G., Ghorbel, E., \& Gomart, H. (2015). Mix Design and Properties of Recycled Aggregate Concretes: Applicability of Eurocode 2. International Journal of Concrete Structures and Materials, 9(1), 1-20. https://doi.org/10.1007/s40069-014-0087-y

[27] Matias, D., De Brito, J., Rosa, A., \& Pedro, D. (2013). Mechanical properties of concrete produced with recycled coarse aggregates - Influence of the use of superplasticizers. Construction and Building Materials, 44, 101-109. 
https://doi.org/10.1016/j.conbuildmat.2013.03.011

[28] Chakradhara Rao, M., Bhattacharyya, S. K., \& Barai, S. V. (2011). Behaviour of recycled aggregate concrete under drop weight impact load. Construction and Building Materials, 25(1), 69-80. https://doi.org/10.1016/j.conbuildmat.2010.06.055

[29] González-Taboada, I., González-Fonteboa, B., MartínezAbella, F., \& Carro-López, D. (2016). Study of recycled concrete aggregate quality and its relationship with recycled concrete compressive strength using database analysis. Materiales de Construccion, 66(323). https://doi.org/10.3989/mc.2016.06415

[30] Martínez-lage, I., Martínez-abella, F., Vázquez-herrero, C., \& Pérez-ordóñez, J. L. (2012). Properties of plain concrete made with mixed recycled coarse aggregate. Construction and Building Materials, 37, 171-176. https://doi.org/10.1016/j.conbuildmat.2012.07.045

\section{Contact information:}

\section{Saied KASHKASH}

Marcel Breuer Doctoral School,

University of Pécs,

Hungary, 7624 Pécs, Boszorkány Street 2

E-mail: saied.kashkash@mik.pte.hu

\section{Zoltan ORBAN}

(Corresponding author)

Faculty of Engineering and Information Technology,

University of Pécs,

Structural Diagnostics and Analysis Research Group,

Hungary, 7624 Pécs, Boszorkány Street 2

E-mail: orbanz@mik.pte.hu

\section{Oliver CZOBOLY}

Beton Technológia Centrum Ltd

Hungary, 1107 Budapest, Basa Street 20-22.

E-mail: czobolyo@btclabor.hu 